\title{
Control over Stories of Illness and Life
}

\author{
The case of a career media participant \\ turned media professional
}

\section{Espen Ytreberg}

Department of Media and Communication, University of Oslo, Norway

\begin{abstract}
This article discusses the relationship between nonprofessional media participation and the professional handling of participants. It expands on the case of "Karen", who related her life-threatening illness and patient experience in a broad range of media before transitioning into professional communications work for a health organization that required her to recruit other patient-participants. The article contributes to research on media participation by focusing on the blurred boundaries between professionals and nonprofessionals. It describes how relationships between the two can be characterized by tensions and dilemmas that are closely tied to issues of status and control. Karen's case is instructive in the particular light it sheds on such matters and on how control over the mediated telling of a life story is exercised.
\end{abstract}

Keywords: media participation, media organizations, media professions, patients, health

\section{Introduction: Communicating illness through media participation}

The struggle of a person who has contracted a serious disease is not only a matter of handling the given medical condition but also one of handling communicative conditions and challenges (Frank, 1995; Hallin \& Briggs, 2016). When taken in and treated by the medical institution, the sick person becomes a patient; in a media-institutional context, $\mathrm{s} /$ he becomes a potential media participant. When considering the media participation of patients, then, one must take into account both the basic need to communicate one's life condition and the institutions of health and media that are involved in making such participation possible. That institutional context is both a political and social one. At stake is the authority and legitimacy of medical and media professionals, the status of patients, and their public voice.

The impulse to narrate the story of one's illness has deep human roots. Research in the medical humanities on life stories and the telling of them tends to explain the sick person's urge to narrate with reference to the constitution of selfhood itself: 'Stories do not simply describe the self; they are the self's medium of being', says Arthur Frank in

Ytreberg, E. (2019). Control over stories of illness and life: The case of a career media participant turned media professional in Nordicom Review, 40(2): 37-48. doi:10.2478/nor-2019-0023. 
the context of patients telling stories of their illness (Frank, 1995: 53). This is debatable as a general proposition; an account of such self-narration must consider that contextual factors can be basic ones also. In historical terms, the impulse of patients to self-narrate was strengthened in the post-war move away from patients being conceived of as passive objects of medical expertise toward an emphasis on them as active, empowered subjects (Hallin \& Briggs, 2016). At the same time, the reach of medical institutions has expanded, in part by the expansion of the welfare state and in part through 'medicalization' and 'biomedicalization'. These are processes whereby more and more health problems and their interventions come to be understood in medical terms, as constellations of risks to be anticipated and avoided by means of medical and lifestyle optimization (Adams et al., 2009; Clarke et al., 2010). At the same time, illness has come to be seen in more individualized terms, as a situation that requires the afflicted persons to administer both their affects and rational choices - what Stage (2015) calls an entrepreneurial practice of illness in the context of social media.

Vitally, media developments have presented patients with more opportunities for reaching large audiences and thereby gaining a public voice. In the extant literature on media participation, sick people and patients have not been studied much, although a body of recent research does look into the ways easy-to-access web facilities such as blogs are used to tell stories via the media (for an overview, see Stage, 2015). However, the encounter with editorial media and professions is not considered, and they remain important in questions of participants' access to legitimate public voice. As for the media organizations' interests in recruiting participants, they routinely need human interest cases for their stories about illness and health, which is a popular topic of journalism and other factual genres (Briggs \& Hallin, 2016). Research has demonstrated the importance of individual cases to journalistic media coverage generally (e.g., Birks, 2017; Figenschou, 2017; Mullan et al., 2006; Palmer, 2018). In the context of journalism on health and illness, the media need patients to put a 'face' on the disease.

This constant need for patient cases is one process that supports talking about participation as a broad tendency in the current media (Burger, 2015; Enli, 2007). This need, like reality TV's need for ever-new recruits, produces a group of particularly active participants termed 'repeat', 'return', or 'serial' participants. They participate in a range of media over an extended period of time, so that they gain a certain expertise, an exemplary status in the eyes of audiences and followers and a degree of personal exposure of their lives. This status can be exchanged not only for public voice and for visibility but also for revenue such as bloggers promoting products and various kinds of performance fees. A career, although an unconventional one, seems to be articulated in this form of labour for various financial and nonfinancial remuneration.

In the case of 'Karen', a career media participation was exchanged for a career as a professional communications worker. Her work to control the telling of her life story with illness was transformed as her career status changed. Her case was relatively typical of the kinds of media participation career the present media situation affords. It became unusual when Karen transitioned into professional communications work for a health organization that required her to recruit other patient-participants, throwing her self-representation into a different light. Her case highlights from an unusual and instructive angle how control over a personal story of illness becomes articulated in a field of media-institutional and professional forces. 


\section{Media participation and the professional/nonprofessional divide}

The first wave of research on media participation in large-scale and mainstream media (as distinct from research on smaller-scale 'participatory media') concentrated particularly on broadcast formats that relied on the participation of so-called 'ordinary people' (e.g., Grindstaff, 2002; Jenkins, 2006; Syvertsen, 2001). These were primarily entertainment and reality TV formats, although other genres and formats were also discussed. According to some research, the social status of these participants was lower than that of traditional media sources (Karlsen et al., 2009). Their motives and general believability tended to be criticized in the media. Research straddled the balance between keeping a critical distance toward the organizations and professions producing these programmes and a conditional support for the idea that a real form of public voice might still be made available to participants. A somewhat similar balancing act came with the affordances of digital media for participation; blogs, for instance, seemed to lower the bar for voicing and discussing the experience of illness publicly. At the same time, the blog context tended to be a low-status one, associated with forms of self-promotion and self-absorption.

A second phase in research on media participation focused more on the disillusions and withdrawals of participation. It pursued parameters of trust/distrust and engagement/disengagement as formulated by the convenors of the 2018 ICA preconference 'The participatory turn 10 years later' (also see Casemajor et al., 2015; Syvertsen, 2017; Vanhaegt, 2018). The changes of orientation might have been related to a more general decline of trust in the digital media, following exposés of digital surveillance and manipulation. This second phase of research highlighted issues of status and trust; the lower the participant's status and esteem, the greater the risk of meeting with aggression and negative feedback from audiences and followers. It also brought an awareness of how deciding to participate was one side of a coin whose other side was deciding to downscale or withdraw from participation. This article follows a career trajectory of engagement and then partial withdrawal from the media by a type of high-status, hightrust participant that has been little studied in the research.

As a consequence of extended participation in the area of proliferating platforms and participation-based formats, some researchers have talked of 'blurred boundaries' between professionals and nonprofessionals in the media (e.g., Deuze \& Jenkins, 2008; Jenkins, 2006). A media participant can become quite media-savvy with experience in terms of understanding the genre, its audience expectations, and production requirements. That goes especially for those one might call career media participants. If such a blurring levels the playing field of professionals and nonprofessionals in terms of power and control, this will have important consequences not only for the media and their audiences but also for the lives of those existing in this in-between situation.

However, so far research has not told us much that is concrete about such an inbetween situation. It has provided an initial and general characterization of contemporary life as one being led in the media rather than with it (Deuze, 2012). Theoretical pronouncements at this general level, although helpful in an initial and overviewing sense, do not aid much in making distinctions. Lives led in and with the media are liable to be just as concretely and finely shaped by societal, discursive, economic, and organizational forces as other lives. 


\section{Methodology of the single case}

The value of a single case depends partly on the researcher being able to capture that case's intrinsic richness, partly on showing how it could be symptomatic of some more general themes. In pursuing such a double ambition, this article is influenced by Klawiter's (2004) and Stage's (2015) one-case studies, which place the individual patient story within a wider socio-political and discursive context. It also draws inspiration from Garfinkel's (1967) classic sociological study of 'Agnes', whose troubled transgender self-identity clashed with the societal expectations of Cold War middle-class America. Here, the basis for generalization can be found in general social norms of behaviour and life values encountered by Agnes over the course of her life. The tensions and richnesses of that individual case will illuminate more general norms.

I originally recruited Karen as an informant for a larger research project on health and the media. She was approached initially in her role as a communications professional in one of Norway's patient organizations. She underwent an interview using the project's standardized interview guide, which focused mainly on her organization's media relations and strategies. This guide included questions about the organization's work to provide patient cases for the media, at which point it became clear that Karen herself had been such a case on numerous occasions. Already during that first interview, she signaled a preference to be acknowledged primarily as a professional rather than as a patient or media participant. To allow for this, I improvised an arrangement whereby she answered in her role as a patient organization professional during that first interview. She would hold back on her patient experiences, which would be the subject of a separate interview.

This was mostly carried through in the second interview, but in subsequent contact that separation was in practice not rigidly adhered to. As Karen herself readily acknowledged, stories she told about her life as a patient would invoke her organizational life experiences and vice versa. I was struck by the extent and richness of her media experiences as well as by her transition from patient participant to communications professional, a main event in her life by Karen's own account. I decided to pursue her as a research case, by whichever methodical means I could muster. After a period of engagement, I had produced an opportunistically gathered but also rich body of empirical material. It included three long-form, semi-structured interviews, two shorter periods of observing her during work, and a number of informal conversations of varying length, all done in a seven-month period in 2018. I also analysed the extensive archived traces of her media activity, although I refrained from expanding on this in writing for reasons of anonymization. As a researcher, I found in Karen what Yin (1989) calls an 'intensity case' in the sense of being particularly information-rich. As an interlocutor, I was struck by her reflective abilities and found myself continually learning from her.

As for anonymization, this is a particular challenge in the case of informants who have left extensive traces in the media. Steps have therefore been taken in addition to changing her name and withholding that of her patient organization. I have also chosen to withhold the specific character of her disease, since that would indirectly identify her and the patient organization she is affiliated with. To make Karen less digitally searchable, I have refrained from directly citing any media statements by or about her, instead paraphrasing. Karen has read and commented on drafts of this article to ensure that the extent of identification is acceptable to her. 


\section{Patient life and media life}

The adult life of Karen was characterized by a string of life-threatening diagnoses. She underwent a series of treatments that, although life-saving, have in themselves been severely deleterious to her health. Karen was first diagnosed in 2009 at the age of 23 when she was starting higher education. Although her affliction was serious, initial prognoses were relatively favourable. Karen had searched for information online about people in a similar position but found little in Norwegian that was relevant. She also felt that she needed an alternative to the update e-mails she had been sending to family and friends about her condition. In the fall of 2009, Karen started her own blog, where she provided extensive and running updates on the progress of her disease, its treatment, and its impact on her life.

Karen underwent treatment and was pronounced symptom-free but suffered from fatigue, which prevented her from advancing with her studies. She was still able to keep her blog up, and its readership and number of comments grew. In the spring of 2010, Karen enlisted as a volunteer for a nonprofit patient organization while taking further education courses. Later that year, her affliction was found to have returned, this time requiring a more invasive and risky treatment. It eventually removed Karen's symptoms but took a long time to recover from. As her physical condition improved, she appeared in numerous newspaper and journal features, on local and national radio and television, and she wrote informational articles.

In 2012 came a second return of Karen's disease, this time requiring a more invasive form of treatment and presenting still tougher mental challenges. Her round of treatment had been documented in part by a broadcaster that made her part of a TV series. This appearance caused a considerable increase in her digital readership, which now also included a dedicated Facebook page following up her book from 2015. This was a narrative of her life experiences as a patient.

In 2014, Karen began a work training internship at a patient organization and secured a part-time job as a communications professional at a second patient organization. From 2017 to the time of writing, she has worked at this latter organization, doing internal and external communications work and producing various forms of media content. From the start in 2017, liaising with other patients about doing media appearances has been one of her tasks. The period of Karen's professional career has coincided with a marked decrease in her media activity. She has stopped updating her blog and Facebook page.

\section{From a patient to a professional}

The years 2014-2015 were pivotal ones for Karen. At this time, she was at the height of media fame with significant and established exposure on her blog, Facebook page, and numerous appearances in print and broadcast media. She also did a considerable number of public talks for various health organizations about her patient experiences. At that time, she had been cured of her disease, although significant after-effects lingered. In a narrative sense, the story of her experience with illness was concluded. A relatively common feature in the self-narration of patients is the 'restitution plot' (Frank, 1995: $77 \mathrm{ff}$ ), the tale of fighting out of illness and arriving into restored health. As Rettberg (2014) points out, the medium of the blog affords goal-oriented narratives that are episodic and ongoing, but eventually they feature a form of closure. Karen's blog roughly 
followed this form of plot over the long arc of its many periodical publications from 2009 to 2015. The publication of her book, which summarized her life since falling ill, also served as a summary of her process toward restitution.

At that time, the significant level of public exposure had brought opportunities for utilizing Karen's visibility and audiences' identification with her. As she began working first as a trainee and then as a communications professional, she scaled down her media exposure drastically. Karen did see an opportunity to turn her public visibility into its own full-time career, but it did not appear sufficiently attractive to her, as she explained in a research interview:

I could almost have gone for doing the talks and living off of them. But at that time I felt that I had experienced a lot of uncertainty in my life the last years, I needed something secure and permanent, and so I went in another direction and applied for a permanent job. [...] That meant concentrating more on getting well and less on maintaining readership on social media or my blog. I just felt I was finished with that, I didn't have more to give really. If I were to live off the talks I would have had to keep relevant and would have felt I had to expose myself quite a lot for people to be able to find me.

For Karen, living off public appearances would largely be a freelance work situation, highly precarious work and correspondingly demanding even for those at full physical strength. Stability, job security, and a steady income were Karen's reasons for preferring permanent employment to freelance work life. Also, she wanted to pursue the kind of professional career she had been aiming for before the disease set in.

In other words, Karen came to see a professional career in contrast to a media participation career, and the transition from a patient to a professional more as a break than a continuum. This break was not just a matter of changing her career prospects but also one of shedding a media persona she had come to see as limiting:

I don't like to mix those roles. Personally speaking I don't want to be associated with [name of disease] for the rest of my life. That's one of the reasons why I quit my social media activities, you sort of have to move on. [...] Sometimes I want to be a professional and only that. I am moving more and more away from the patient role. You kind of have to move on, and I feel more like going the professional route.

It should be noted that this emphasis on a clear break was not only a break with Karen's media activities. She was concerned to separate her new life as a professional life from her former role as a patient. She wanted her due for doing her job professionally, not out of sympathy or pity for her suffering from illness.

It is well known from the research literature on media participation that both the wide distribution of media content and its permanent digital availability presents challenges to media participants (see Duckert \& Karlsen, 2017; Palmer, 2018). Karen had increasingly experienced that people in her lifeworld addressed her based on seeing her on TV or reading about her. Counting herself a relatively introverted person, she found it tiring to deal with this widely distributed version of herself, even though people were generally appreciative. She had noted with some dissatisfaction that Facebook posts of a personal nature seemed to attract more attention than ones she posted in a professional capacity. Karen also thought she could discern in some of the responses a pitying "poor 
you" attitude that she resented. She realized that with the Internet making much of this content permanently available, the attention might not go away easily. She was worried that she might be permanently associated with her disease in the public's mind and that it would come to define her like a 'brand on the forehead', as she put it.

Although Karen wanted to keep the roles of patient and professional separate, in practice her role and persona as a patient would follow her into her work life. She did not stop doing public talks and media appearances, although she reduced the latter markedly. Instead, they became an element in her professional communications work. A main reason was that Karen was required to find patient cases to supply for the media, and as it happened, Karen was her own most convenient go-to example. She was a proven media performer; she held a key to her organization's visibility. In the context of her organization, this was a strong asset. In certain respects, it placed Karen on a level above her superiors, which caused her to have mixed feelings:

[...] this is sort of embarrassing to talk about, but the problem is that often the journalists know of me in advance and that means they want me, but as a communications professional I may think that the proper thing is to give this to the manager or chairman of the board. But then it's almost as if the reaction [from the journalists] is: 'well if we can't have you, we don't have a story'. So that has meant that I have been featured more than I feel is natural and comfortable, really, because we're a small organization and we need all the media attention we can get.

In terms of her work relations, Karen found this form of continued media exposure embarrassing and stressful. She felt that she was implicitly disrespecting the organization's hierarchy of command when the media wanted to pose questions she felt her superiors should have had the right to answer. This combining of the roles of professional and patient also caused other complications in her everyday work life. For instance, as the organization's only communications staffer, Karen would have to write up a story about herself as a media participant.

\section{Being recast as a patient}

One of Karen's continued media activities as a professional communications worker was to host media productions where she interviewed patients. In some instances, she would also relate her own patient experiences. When doing so, Karen herself scripted the segues and transitions that had to be made between her roles of patient and professional. As a host she was in control not only over the life stories of other patients, but also of her own story, and of segueing between telling that story and framing it on behalf of the instition she represented.

In other contexts, her measure of control was considerably more circumscribed. The potentials for tension between the two roles were played out in a public meeting where Karen was booked by her former employer in the patient organization field, to do a talk about chronic fatigue as a challenge to ex-patients. This former patient organization was one that her subsequent employer needed to stay on good terms with. Thus Karen was required to cooperate and had done so on numerous occasions before, speaking at her former employer's public events about her patient experiences. This one she did as part 
of her working time, at the request of her employer. She wanted to strike the balance of appearing there as a professional representative, not merely as a patient. This brought the risk of a clash of interests. On the phone with an event representative, Karen had negotiated in advance a preliminary compromise, which included being introduced as a representative of her present organization. In the programme, she appeared half patient, half organizational representative: ' $17.35-17.50$ : Patient history. By Karen from [name of patient organization]'.

In a conversation immediately preceding the talk, Karen had reflected on the stresses of trying to make her former employer treat her as a professional, not merely a patient:

It is hard to balance the need to make demands of [name of former employer].

At first these talks were just fun, you know, but later I started thinking: it costs energy to do this, so what am I getting out of it?

In her earlier phone conversation with the former employer, further details of her present organization's exposure had not been discussed in detail. Karen's own understanding was that she would be able to place a rollup for her organization where she wanted in the localities. She brought the rollup to the event, along with brochures and other informational material. It turned out that space had been marked out for Karen's rollup and info material in an adjacent room, semi-separated from the meeting room proper. This spatial setup meant that she and her material would be placed more or less as far as possible from where she would stand as a speaker. For the purposes of fronting her organization, it did not make much sense.

In the situation, Karen accepted this without discussion and gave her talk. The response from an audience mainly consisting of patients, survivors, and their next of kin was strong and affirmative. It may have been occasioned in part by the enthusiastic framing of her talk by the event hosts. It placed her squarely in the role of a patient, a contrast to the professionals otherwise featured at the event, even as it recommended her strongly to the audience:

Intro to Karen, segueing from the talk of a medical researcher: 'And now a completely different kind of expert.'

Outro, segueing from Karen to the next speaker: 'It is always powerful to listen to you, Karen. [...] I am so impressed by your optimism. [To the audience] She describes so wonderfully well how fatigue feels, what you do to cope and what is still possible.'

Afterwards, Karen expressed displeasure about the event. The need to stay on good terms with her previous organization had held her back from making a fuss about the rollup, she said. For Karen, it had turned out to be a condition of working as a professional in the health field that organizational and strategic concerns beyond her control might at times push her back into the role of a patient. At times, she seemed to be more valuable to her employer as a patient than as a professional. According to Karen herself, this was a nuisance more than something intolerable. It was also something largely beyond her power, however, and a form of exploiting the participant that she was now in a particular position to notice. 


\section{Distancing from fellow patients, and responsibility for them}

When Karen first started a blog in 2009, initially she did so with a view to updating her family on her medical situation. Like many patients in her situation, she also wanted to exploit the possibilities of the Internet for seeking out people in the same predicament as her. As she described it, the impulse was primarily a social one:

I felt very alone. Blogging hadn't taken off so much at that time, at least not in the world of [her disease], you didn't have many bloggers [with her disease]. So I didn't have anyone in my situation I could seek out, and I really missed that.

Fostering a sense of togetherness with others was a key motive in the startup phase. Responses to her first blog updates from November 2009 showed a number of instances where the messagers belonged to Karen's circle of family and friends. In a few instances, they divulged personal information such as when a relative referred to Karen being on a visit to the relative's house in a message.

From the blog's beginning, a key aim of Karen's was to help inform those afflicted with her disease and their nearest ones about it, how to combat the disease and live with it. When comments started coming in on her blog site, her motives by her own account expanded to providing information more generally. This motive, which Hawkins (1999: 128) calls 'didactic', is a common one for people telling their illness story publicly. The didactic motive tends to produce stories that blend factual information with a spirit of personal openness and mutual support. This motive is common among patient bloggers and also to other nonprofessional participation, for instance in news media. For a long time, Karen's blog worked on these joint premises of sharing an emotional, social experience and distributing useful information. It was a form of emotional labour requiring Karen to 'manage her heart', as Arlie Hochschild (1983) put it, staying in her role as friendly, caring, and accessible.

Karen's relationship to her fellow patients on digital and social media underwent a shift around the time when she moved into professional work. She started to put less work into posting and responding on her blog and Facebook page. She noted a certain instrumentalism coming on, for instance in the way she set up the Facebook page, which marketed her book: '[...] that was kind of a cynical page, I knew I had to use my story and what I went through in order to attract followers'. In a conversation with me, Karen somewhat wistfully contrasted the instrumentalism of this Facebook marketing with her own attitude in 2009: 'I started as this naive 23-year-old, completely clueless about both the illness and how to speak about it.' At that time, by her own account, she was trying out digital media out of some more primal need, without consciously knowing either how or why she was doing it.

By 2015, Karen's attitude had changed toward the commenters on her blog among others. Their relationship to her was also different since they were now so numerous that the great majority of them did not know her personally. Her last regular update on the blog dealt with her voluntary work prior to attaining a trainee position. It received a highly enthusiastic message from someone who had seen Karen on a television appearance enthusing about how inspiring her positive attitude was. This messager did not self-identify as a patient, so there were no grounds for Karen to include her in a fellowship of sufferers. She had always kept a friendly tone in her posted responses to 
commenters and did so also in this instance, but her answer was brief, and she referred the commenter to her promo Facebook page.

The increased distance did not necessarily mean that Karen had stopped caring about fellow patients. As a communications professional, however, her caring had to be reconciled with being in charge since she was now one of those responsible for patients telling their stories. In some cases, she was more or less solely in charge, as in the above-mentioned interviews and in seeking out patients for journalists to use as cases. Karen's sense of responsibility if anything seemed to have grown with her ascension to a certain power and responsibility. At the same time, she had formed a rather bleak view of the ways journalists treat patients:

I think that is just nauseating. I have been that patient case many times and the whole thing is just so cynical and gross. I think it's awful, really. That's why I watch closely, at least now that I am working here [at her patient organization] that those who do it for us get a really great follow-up, because I've been that person myself.

The intensity of Karen's reaction was probably connected with her particular insight into the tensions and conflicts between patients' and media professionals' interests. It might also reflect a worry that the differences in the needs of the two parties were hard to reconcile.

\section{Positivity and going it alone}

As mentioned above, something in the public telling of life stories, in standing out publicly as a patient case, might rhyme with a general individualizing tendency in contemporary society. It requires the sick person to be a kind of entrepreneur who assumes responsibility for handling the risks and opportunities of treatment and associated lifestyle choices. This tends to remove the sick person from collectives so that career patient-participants can end up in a situation of not quite belonging either to the communities of everyday life or to professions and organizations. Since becoming a communications professional, Karen distanced herself to a certain degree from the communities she had cultivated on social media. Also, her professional foothold was somewhat limited after her transition, partly because her experience as a media participant was still being called on and partly since she was physically able to work only part-time due to the after-effects of the disease.

These conditions invite a search for meaning and motivation that is also individualized. A feeling of having to go through it alone is not unusual among those with lifethreatening illnesses. Both on her blog and in her book, Karen described the feelings of deep, existential loneliness that can come over a seriously ill patient who realizes how far off a cure can be, how pain can wear you down over time, and how close to impossible it is for the physically healthy to understand. All of this must be handled in the life of a patient. In the case of patients who are media participants, it also must be communicated for audiences in some measure. A story of going through it alone or, more precisely, a story of being left to find within oneself the resources for coping with life and disease will often have to be told.

As the response from Karen's appreciative blogger mentioned above illustrates, positivity is a recurring concept in the vocabulary of patient-participants. In recent intellectual discussion of illness and health, the concept of positivity and perceived attitudes 
behind it have received harsh criticism from the cancer patient and intellectual Barbara Ehrenreich (2010), among others, for putting too much on the shoulders of patients and for wrongly arguing that a patient's everyday attitude toward a physical disease impacts the course of that disease. Karen was aware of the dangers of positivity becoming a one-sided imposition on the patient from outside. She promoted positivity as an ideal orientation, something not to abandon, more than something sick people should be required to feel at any given point. A blog post Karen wrote in 2014 while recovering from her last major round of treatment contained several recommendations for patients in similar situations. The last recommendation was to focus on the positives. Here she explicitly acknowledged the problematic sides of being told to think positively. At the same time, according to Karen, there was something to be said for it. Sick people are in a tough spot, she wrote, but some things could always have been worse. There is always something to be grateful for, she concluded.

The advice was in itself quite simple, even in a sense banal, but these were also modest claims that allowed for feeling pained, lonely, or burdensome. At the same time, much hinged on that modest claim for Karen - not just her feelings of responsibility in communicating with other afflicted but her own life management. And even the suggestion to try and reach beyond the troubles toward something positive can be too much for some patients to live up to. It is the harsh reality of long-term, life-threatening illness that it can wear down one's strength and will. In the face of such conditions, positivity will be a very real challenge. After her talk for fellow patients at her previous employer's event, a main concern of Karen's was whether she succeeded in communicating that positive thinking is necessary because the patient has no alternative but to tell herself that the situation can be managed and can get better, even though the sick person will have to do it alone and find the necessary mental strength in spite of physical weakness.

\section{Conclusion}

In Karen's case, the ideal of positivity was in a sense doubly understandable as an an attitude taken to handle not only life as a patient-participant but also the fact that a move into media professionalism did not erase precariousness; instead, it took on the forms of part-time employment and intermittent, involuntary returns to the role of a participant. It is not precisely wrong to say in Karen's case that a blurred boundary existed between her nonprofessional and professional status, but neither is it precisely right. Rather, professional status was a moving goalpost, a privilege that kept eluding her in its fullness. Still, the transition was real in the sense of confirming that she was qualified for the job. Her status as a career media participant had been conferred by means of constant exposure. It was more ephemeral and more dependent on distant others.

The unusual nature of Karen's experience laid partly in the way she transitioned from a participant to a professional, but especially in the way her job required her to recruit other patient-participants. This is a case in which the exceptional case illuminates more general social norms - in this case, norms for how media professionals handle media participants and for how media participants handle themselves. As for the latter, Karen underwent a process of distanciation from other media participants that could be seen more generally as the cost of professionalism relative to an emotional rapport between patient-participants and their followers. She also came to grapple with the responsibility organizations and 
professions have for how participants are treated. If Karen's characterizations of 'nauseating', 'cynical', and 'gross' strike outsiders as intense, it could be because she was in the particular position of living both experiences in turn so that she would feel a basic tension between the perspectives and concerns of the participant and the professional.

\section{References}

Adams, V., Murphy, M. \& Clarke, A. E. (2009). Anticipation: Technosicience, life, affect, temporality. Subjectivity, 28(1): 246-265.

Birks, J. (2017). 'Moving life stories tell us just why politics matters': Personal narratives in tabloid anti-austerity campaigns. Journalism, 18(10): 1346-1363.

Briggs, C.L. \& Hallin, D. (2016). Making health public: How news coverage is remaking media, medicine, and contemporary life. London: Routledge.

Casemajor, N., Couture, S., Delfin, M., Goerzen, M. \& Delfanti, A. (2015). Non-participation in digital media: Toward a framework of mediated political action. Media Culture \& Society, 37(6): 850-866.

Clarke, A.E., Mamo, L., Fosket, J.R. \& Fishman, J.R. (eds.) (2010). Bimedicalization: Technoscience, health and illness in the U.S.. Durham, NC: Duke University Press.

Deuze, M. (2012). Media life. Cambridge: Polity Press.

Deuze, M. \& Jenkins, H. (2008). Editorial: Convergence culture. Convergence, 14(1): 5-12.

Duckert, F. \& Karlsen, K.E. (2017). I medienes søkelys: Eksponering, stress og mestring [In the media searchlight: Exposure, stress and handling]. Oslo: Gyldendal Akademisk.

Ehrenreich, B. (2010). Smile or die: How positive thinking fooled America and the world. London: Granta.

Enli, G. (2007). The participatory turn in broadcast television: Institutional, editorial and textual challenges and strategies. Oslo: Unipub.

Figenschou, T.U. (2017). Patient narratives: Health journalists' reflections, dilemmas and criticism of a compelling journalistic tool. In B. Kjos Fonn, H. Hornmoen, N. Hyde-Clarke \& Y. Benestad Hågvar (eds.), Putting a face on it: Individual exposure and subjectivity in journalism (pp. 235-256). Oslo: Cappelen Damm Akademisk.

Frank, A.W. (1995). The wounded storyteller: Body, illness and ethics. Chicago: University of Chicago Press.

Garfinkel, H. (1984). Studies in ethnomethodology. Oxford: Blackwell.

Goldberg, G. (2010). Rethinking the public/virtual sphere: The problem with participation. New Media \& Society, 13(5): 739-754.

Grindstaff, L. (2002). The money shot: Trash, class, and the making of TV talk shows. Chicago: University of Chicago Press.

Hawkins, A.H. (1999). Patography: Patient narratives of illness. Culture and Medicine, 171(2): 127-129.

Hochschild, A.R. (1983). The managed heart: Commercialization of human feeling. Berkeley: University of California Press.

Karlsen, F., Sundet, V. S., Syvertsen, T. \& Ytreberg, E. (2009). Non-professional activity on television in a time of digitalisation: More fun for the elite or new opportunities for ordinary people? Nordicom Review, 30(1): 19-36.

Klawiter, M. (2004). Breast cancer in two regimes: The impact of social movements on illness experience. Sociology of Health \& Illness, 26(6): 845-874.

Jenkins, H. (2006). Convergence culture: Where old and new media collide. New York: NYU Press.

Mullan, F., Ficklen, E. \& Rubin, K. (eds.) (2006). Narrative matters: The personal health essay in medical policy. Baltimore: The Johns Hopkins University Press.

Palmer, R. (2018). Becoming the news: How ordinary people respond to the media spotlight. New York: Columbia University Press.

Rettberg, J.W. (2016). Blogging. Cambridge: Polity Press.

Stage, C. (2015). Sygdom på sociale medier - Som biologisk medborgerskab og affektivt arbejde [Illness in social media - as biological citizenship and affective work]. Kultur og klasse, 43(120): 103-124.

Syvertsen, T. (2001). Ordinary people in extraordinary circumstances: A study of participants in television dating games. Media Culture \& Society, 23(3): 319-337.

Syvertsen, T. (2017). Media resistance: Protest, dislike, abstention. Palgrave. doi: http://doi.org/101007/9783-319-46499-2

Vanhaegt, A-S. (2018). The need for not more, but more socially relevant audience participation in public service media. Media Culture \& Society, 41(1): 120-137.

Yin, R. (1889). Case study research: Design and methods. London: Sage.

Copyright: (C) 2019 The Author(s) and Nordicom. This is an open-access article distributed under the terms of the Creative Commons Attribution 4.0 International License (CC BY-NC-ND 4.0). 